\title{
Plantas de cobertura no controle das perdas de solo, água e nutrientes por erosão hídrica
}

\author{
Dione P. Cardoso ${ }^{1}$, Marx L. N. Silva ${ }^{2}$, Gabriel J. de Carvalho ${ }^{3}$, \\ Diego A. F. de Freitas ${ }^{2}$ \& Junior C. Avanzi ${ }^{4}$
}

\begin{abstract}
RESUMO
Plantas com alto índice de cobertura e elevada produtividade de fitomassa propiciam melhor proteção ao solo, amortecendo o impacto das gotas de chuva sobre a superfície do solo reduzindo, consequentemente, os processos erosivos. Objetivou-se avaliar a influência das plantas de cobertura e dos espaçamentos de plantio no controle das perdas de solo, água e nutrientes por erosão hídrica, visando à conservação do solo. $\mathrm{O}$ experimento foi conduzido em um Argissolo Vermelho-Amarelo, cujos tratamentos foram definidos por três espécies de plantas de cobertura: crotalária júncea, feijão-deporco e milheto e com dois espaçamentos entrelinhas $(0,25$ e 0,50 m). Para a quantificação das perdas de solo, água e nutrientes, utilizaram-se parcelas de $4 \times 12 \mathrm{~m}$ em que a maior dimensão obedeceu ao sentido do declive. Nos meses de dezembro e janeiro ocorrem os maiores valores de erosividade requerendo, neste período, melhor cobertura da superfície do solo. O feijão-de-porco foi a espécie que apresentou maior potencial no controle dos processos erosivos; quanto ao espaçamento a melhor proteção do solo para todas as culturas foi obtida no espaçamento de $0,25 \mathrm{~m}$, propiciando menores perdas de solo, água e nutrientes.
\end{abstract}

Palavras-chave: crotalária júncea, feijão-de-porco e milheto

\section{Cover crops to control soil, water and nutrient losses by water erosion}

\begin{abstract}
Cover plants with high coverage index and biomass productivity provide a better soil protection, cushioning the impact of the raindrops on the soil surface, thus reducing the erosion process. The objective of this study was to evaluate the influence of cover crops and plant spacing in the control of soil, water and nutrient of this study losses by water erosion, aiming the soil conservation. The experiment was conducted in the Red-Yellow Argisol, with three treatments of cover crops; sunn hemp, jackbean and millet, in two row spacing $(0.25$ and $0.50 \mathrm{~m})$. To quantify the loss of soil, water and nutrients, plots of $4 \times 12 \mathrm{~m}$ were used, and the larger dimension followed up and down slope. During the months of December and January there were the highest erosivity values, requiring in this period a better coverage of the soil surface. The jackbean was the species with the highest potential in the erosion control; and the spacing that promoted the best soil protection for all crops was $0.25 \mathrm{~m}$, providing lesser losses of soil, water and nutrients.
\end{abstract}

Key words: sunn hemp, jackbean and milhet

\footnotetext{
Universidade Federal do Tocantins, Rua Badejós, Chácaras 69 a 72, Zona Rural, CEP 77402-970, Gurupi, TO. Fone: (63) 9947-4556. E-mail: cardoso.dione@gmail.com

Departamento de Ciência do Solo/UFLA, CEP 37200-000, Lavras, MG. E-mail: marx@dcs.ufla.br; diego_ufla@yahoo.com.br

Departamento de Ciência de Fitotecnia/UFLA. E-mail: gab@dag.ufla.br

EMBRAPA, Centro Nacional de Pesquisa em Pesca, Aquicultura e Sistemas Agrícolas, CEP 77015-012, Palmas, TO. E-mail: junior.avanzi@embrapa.br
} 


\section{INTRODUÇÃO}

O impacto das gotas de chuva sobre a superfície do solo constitui o ponto inicial da erosão hídrica. Em localidades onde a erosividade da chuva é elevada e a superfície do solo se encontra desprovida de cobertura vegetal, pode ocorrer grande degradação com consequentes perdas de solo, água e nutrientes, fatores essenciais para o crescimento e desenvolvimento das plantas. A perda de solo e os elementos que lhe são associados, podem causar danos ambientais, como o assoreamento e a eutrofização de cursos d'água, além de prejuízo econômico ao produtor e à sociedade.

Vários estudos relacionam as perdas de solo, água e nutrientes com as práticas conservacionistas e indicam como manter a produtividade sem prejudicar os recursos naturais (Cogo et al., 2003; Bertol et al., 2004; Guadagnin et al., 2005; Silva et al., 2005; Aguiar et al., 2006; Pires et al., 2006; Carvalho et al., 2007; 2009; Leite et al., 2009). Conforme Bertol et al. (2007), independentemente do sistema de manejo empregado o custo referente às perdas anuais na forma de adubos pela erosão hídrica, é relativamente elevado.

As plantas de cobertura exercem influência sobre essas perdas; portanto, espera-se que uma espécie com alto índice de cobertura e elevada produtividade de fitomassa propicie maior proteção ao solo, reduzindo o impacto da gota de chuva sobre a superfície do solo e, em consequência, o escoamento superficial e a erosão hídrica.

Na região Sul do Estado de Minas Gerais, onde a topografia, precipitação e o tipo de solo favorecem o processo erosivo, torna-se importante o uso de técnicas alternativas para o controle da erosão, como o uso de plantas de cobertura para uma melhor proteção da superfície do solo. Assim, objetivou-se avaliar a influência das plantas de cobertura e dos espaçamentos de plantio no controle das perdas de solo, água e nutrientes por erosão hídrica, visando à conservação do solo.

\section{Material e MÉTODOS}

O experimento foi instalado entre as coordenadas $21^{\circ} 13$, $20^{\prime \prime} \mathrm{S}$ e $44^{\circ} 58^{\prime} 17^{\prime \prime} \mathrm{W}$, na área experimental da Universidade Federal de Lavras - UFLA. A temperatura média anual e a precipitação anual foram de $20,8^{\circ} \mathrm{C}$ e $1.248 \mathrm{~mm}$ em 2007 e de $20,1{ }^{\circ} \mathrm{C}$ e $1.644 \mathrm{~mm}$ em 2008 . As plantas de cobertura foram plantadas em novembro de 2007 sobre um Argissolo VermelhoAmarelo distrófico, apresentando textura superficial e subsuperficial argilosas, com os seguintes atributos químicos na camada superficial: $\mathrm{pHem}$ água, 5,4; P-rem, 2,8 $\mathrm{mg} \mathrm{dm}^{-3}$; $\mathrm{SB}$, 2,5 $\mathrm{cmol}_{\mathrm{c}} \mathrm{dm}^{-3}$; T, 5,7 $\mathrm{cmol}_{\mathrm{c}} \mathrm{dm}^{-3}$; matéria orgânica, $24 \mathrm{~g} \mathrm{~kg}^{-1}$.

Visando à determinação da erosividade, utilizaram-se os dados pluviométricos de precipitação de $10 \mathrm{em} 10 \mathrm{~min}$, referentes ao período de dezembro de 2007 a março de 2008, obtidos na Estação Climatológica Principal de Lavras. Posteriormente, calculou-se a energia cinética total de chuvas, conforme Wischmeier \& Smith (1958). Segundo esses pesquisadores o $\mathrm{EI}_{30}$ equivale à multiplicação da energia cinética total (E) de uma chuva erosiva pela máxima intensidade ocorrida em um período consecutivo de $30 \mathrm{~min}\left(\mathrm{I}_{30}\right)$. As chuvas menores que $10 \mathrm{~mm}$, com intensidade máxima menor que $24 \mathrm{~mm}$ $\mathrm{h}^{-1}$, em $15 \mathrm{~min}$, ou energia cinética menor que 3,6 MJ, conforme Maria (1994), foram consideradas não erosivas.

As avaliações das perdas de solo, água e nutrientes, foram realizadas sob chuva natural em parcelas de 4 x $12 \mathrm{~m}$, delimitadas por chapas galvanizadas de 0,40 m de largura, enterradas em $0,20 \mathrm{~m}$. Na extremidade inferior das parcelas foram instaladas caixas coletoras com divisores tipo Geib em que apenas 1/9 da água da enxurrada coletada era transferido para a segunda caixa (Cogo, 1978 a,b). A semeadura foi realizada diretamente nos sulcos, espaçados 0,25 e $0,50 \mathrm{~m}$, no sentido do declive. Não houve preparo convencional do solo nem correção da fertilidade para semeadura.

Os tratamentos foram constituídos de plantas de cobertura em dois espaçamentos: crotalária júncea (Crotalaria juncea L., Fabaceae-Faboideae) em sulcos espaçados 0,25 e 0,50 m; feijão-de-porco (Canavalia ensiformis DC., FabaceaeFaboideae) em sulcos espaçados 0,25 e $0,50 \mathrm{~m}$ e milheto (Pennisetum sp Rich., Poaceae-Panicoideae) em sulcos espaçados 0,25 e 0,50 m. O esquema da distribuição das parcelas no campo é representado na Figura 1.

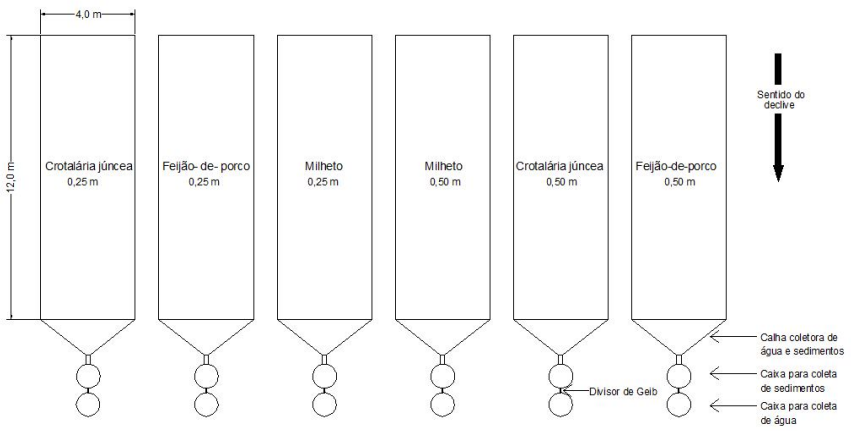

Figura 1. Esquema do experimento no campo

Para a quantificação das perdas de nutrientes, causadas pelo escoamento superficial, foram analisadas as concentrações de $\mathrm{P}, \mathrm{K}^{+}, \mathrm{Ca}^{2+}, \mathrm{Mg}^{2+}$, contidos nos sedimentos da enxurrada.

$\mathrm{O}$ potencial de arraste de sedimentos do solo (PAS) foi determinado com base nas perdas de solo em $\mathrm{Mg} \mathrm{ha}^{-1}$, divididas pelas perdas de água em mm (Zhou et al., 2002; Brito et al., 2005; Pires et al., 2006; Carvalho et al., 2007).

A taxa de enriquecimento do sedimento foi determinada dividindo-se os teores dos nutrientes contidos nos sedimentos da enxurrada, pelos teores determinados no solo (Hernani et al., 1999; Silva et al., 2005). Quando a taxa de enriquecimento da enxurrada foi superior a 1 , significou incremento na concentração de nutrientes e, se inferior a 1 , significou ausência de enriquecimento (Hernani et al., 1999).

\section{RESULTADOS E DISCUSSÃO}

Com relação ao índice de cobertura observou-se, para a crotalária júncea, um porte ereto, com folhas miúdas, cuja estrutura horizontal não foi suficiente para proteger de forma adequada a superfície do solo, havendo tendência de maiores 
perdas (Figura 2). A crotalária júncea é uma planta de crescimento inicial rápido, o que a diferenciou do feijão-deporco e do milheto. Posteriormente, o feijão-de-porco se destacou das demais, apresentando os maiores índices de cobertura do solo devido à forma de sua estrutura horizontal (Figura 2).

O feijão-de-porco apresentou porte rasteiro e folhas alternas, com folíolos grandes elíptico-ovais intercalados entre si, protegendo a superfície do solo do impacto direto das gotas de chuva e reduzindo o escoamento superficial, sendo
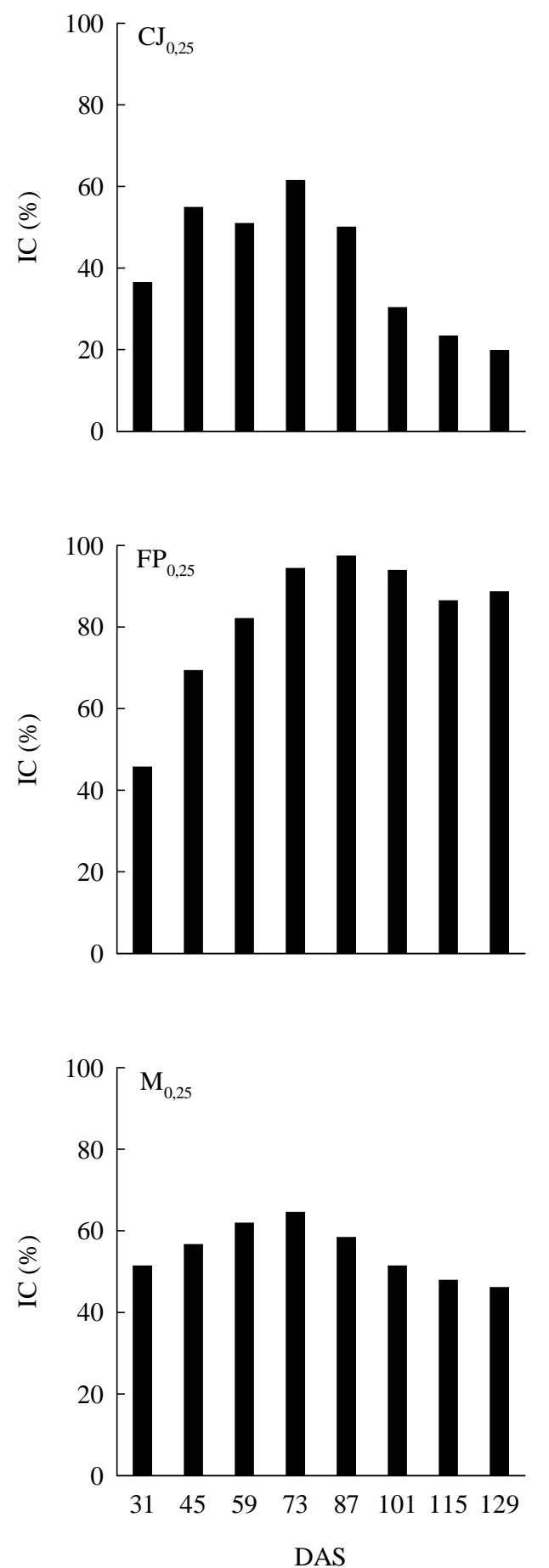

considerado uma espécie muito eficaz como planta de cobertura. Assim, a melhor proteção do Argissolo VermelhoAmarelo foi relacionada ao desempenho desta planta de cobertura. Os maiores índices de cobertura (Figura 2) foram proporcionados pelo feijão-de-porco, sendo de 95,61 e 92,10\%, para os espaçamentos de 0,25 e $0,50 \mathrm{~m}$, respectivamente, e os menores índices de cobertura, pela crotalária júncea, nos espaçamentos de 0,25 m (40,13\%) e 0,50 m (39,04\%).

Os valores mensais, totais e médios de erosividade da chuva e precipitação durante o período do estudo, são apresentados
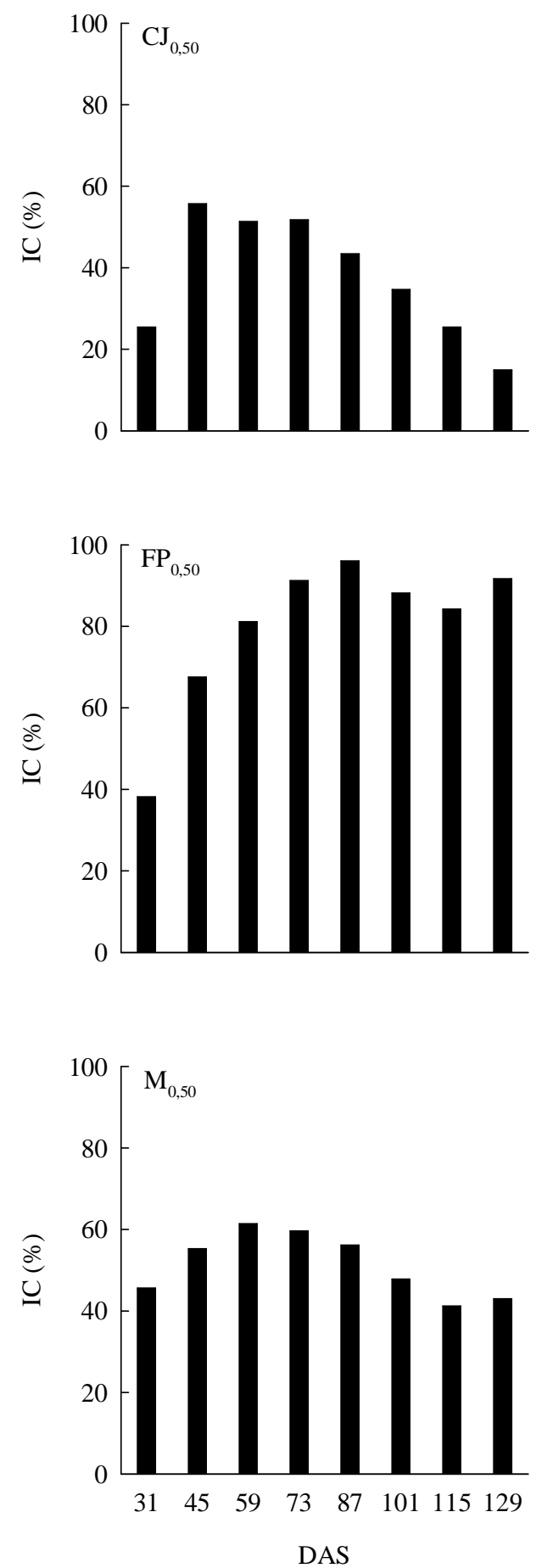

Figura 2. Crescimento das plantas de cobertura representado pelo índice de cobertura (IC) em função dos dias após a semeadura (DAS) de CJ ${ }_{0,25}$ - Crotalária júncea $0,25 \mathrm{~m} ; \mathrm{CJ}_{0,50}$ - Crotalária júncea 0,50 m; $\mathrm{FP}_{0,25}$ - Feijão-de-porco 0,25 m; $\mathrm{FP}_{0,50}$ - Feijão-de-porco 0,50 m; $\mathrm{M}_{0,25}$ - Milheto 0,25 m; e $\mathrm{M}_{0,50}$ - Milheto 0,50 m 
na Tabela 1. Para a erosividade, observa-se a seguinte tendência: janeiro > dezembro > março $>$ fevereiro, com variação de 259 a $1255 \mathrm{MJ} \mathrm{mm} \mathrm{ha}^{-1} \mathrm{~h}^{-1}$ mês $^{-1}$. Na maior parte do tempo de estudo o valor mensal de erosividade esteve acima do considerado crítico, que é de $500 \mathrm{MJ} \mathrm{mm} \mathrm{ha}^{-1} \mathrm{~h}^{-1} \mathrm{mês}^{-1}$ (Rufino, 1986). Observa-se, no mês de fevereiro, que a erosividade foi inferior à do mês de março (Tabela 1), mesmo com valores superiores de precipitação, em razão das menores intensidades da chuva e energia cinética.

Tabela 1. Valores mensais, totais e médios da erosividade das chuvas e precipitação durante o estudo,

\begin{tabular}{lcc}
\hline \multicolumn{1}{c}{ Mês } & $\begin{array}{c}\text { Erosividade } \\
\text { MJ } \mathbf{~ m m ~ h a ~}^{-1} \mathbf{h}^{-1} \text { mês }^{-1}\end{array}$ & $\begin{array}{c}\text { Precipitação } \\
\mathbf{~ m m}\end{array}$ \\
\hline Dez./2007 & 1.240 & 271 \\
Jan./2008 & 1.255 & 230 \\
Fev./2008 & 259 & 205 \\
Mar./2008 & 634 & 175 \\
\hline Total do período & 3.388 & 881 \\
Média do período & 847 & 220 \\
\hline Modificado de Siva e
\end{tabular}

Modificado de Silva et al. (2005)

Na Tabela 2 observam os valores de perda de solo sob chuva natural para o argissolo Vermelho-Amarelo sob crotalária júncea, feijão-de-porco e milheto, nos espaçamentos $0,25 \mathrm{~m}$ e 0,50 m. Em dezembro, as maiores perdas de solo seguiram a sequência crotalária júncea > feijão-de-porco $>$ milheto, dentro do mesmo espaçamento. A crotalária júncea apresentou crescimento inicial rápido porém este crescimento tendeu para altura, ficando boa parte do solo desprovido de vegetação; o milheto apresentou crescimento inicial mais lento, as folhas tenderam a crescer mais, o que proporcionou melhor proteção aos solos que a crotalária júncea (Figura 2). No mês de janeiro (Tabela 2), as maiores perdas de solo no espaçamento de 0,25 $\mathrm{m}$ foram: crotalária júncea $>$ feijão-de-porco $>$ milheto e no espaçamento de $0,50 \mathrm{~m}$, foram: feijão-de-porco > milheto > crotalária júncea. No mês de fevereiro as maiores perdas foram: crotalária júncea > milheto > feijão-de-porco, nos dois espaçamentos (Tabela 2). Em março, em ambos os espaçamentos foram: milheto > crotalária júncea > feijão-de-porco (Tabela 2), sendo que o milheto se encontrava na fase de senescência ocorrendo, em razão disto, as maiores perdas de solo devido à sua baixa produtividade de fitomassa (Figura 2), que não foi suficiente para reduzir o impacto das gotas de chuva sobre a superfície do solo.

As maiores perdas mensais de solo ocorreram no espaçamento de $0,50 \mathrm{~m}$, para as três plantas cultivadas (Tabela 2), sendo que a menor densidade das plantas de cobertura contribuiu para o impacto direto das gotas de chuva sobre a superfície do solo e, em contrapartida, o desprendimento e arraste de partículas de solo. Durante os meses de janeiro e fevereiro a crotalária júncea proporcionou a menor perda de solo para o espaçamento de $0,50 \mathrm{~m}$, o que ocorreu provavelmente porque o maior adensamento de plantas manteve elevada a umidade do solo em fevereiro e o solo apresentou mais próximo à saturação, fazendo com que o escoamento superficial iniciasse antes, sendo as perdas de solo superiores no espaçamento de $0,25 \mathrm{~m}$.

As perdas totais de solo variaram de 0,24 a 2,38 $\mathrm{Mg} \mathrm{ha}^{-1}$, para o feijão-de-porco no espaçamento de $0,25 \mathrm{~m}$ e para a crotalária júncea no espaçamento de $0,50 \mathrm{~m}$, respectivamente. Guadagnin et al. (2005) encontraram perdas de solo semelhantes para o preparo do solo/semeadura direta, com seis e nove anos, para os cultivos feijão/soja, ervilhaca/trigo, milho/soja e aveia/trigo, em um Cambissolo Húmico alumínico léptico e Carvalho et al. (2009) para um Argissolo VermelhoAmarelo sob crotalária júncea em nível. Valores de perdas de solo superiores aos encontrados neste estudo foram obtidos por Leite et al. (2009) em um Latossolo Vermelho-Amarelo ácrico típico, sob preparo convencional morro abaixo, para a cultura do algodão em Mato Grosso. Na região de Lavras, MG, Carvalho et al. (2007) também verificaram valores de perda de solo superiores em um Latossolo Vermelho distroférrico típico sem cobertura vegetal.

$\mathrm{Na}$ Tabela 3 verificam os valores de perdas mensais de água sob chuva natural com cultivo de crotalária júncea, feijão-deporco e milheto, nos espaçamentos 0,25 e $0,50 \mathrm{~m}$. Em dezembro as perdas de água no espaçamento de $0,25 \mathrm{~m}$, foram maiores na crotalária júncea $>$ milheto $>$ feijão-de-porco e no espaçamento de 0,50 m, nos solos sob crotalária júncea > feijão-de-porco > milheto. Em janeiro as perdas de água no espaçamento de 0,25 $\mathrm{m}$ : crotalária júncea > feijão-de-porco > milheto e no espaçamento de $0,50 \mathrm{~m}$ : milheto > feijão-de-porco > crotalária júncea. Em fevereiro as perdas de água no espaçamento de 0,25 e 0,50 m foram maiores no solo sob crotalária júncea > milheto > feijão-de-porco. No mês de março as perdas de água

Tabela 2. Perdas de solo em um Argissolo Vermelho-Amarelo, sob plantas de cobertura, para os espaçamentos de 0,25 e 0,50 m entrelinhas, sob condições de chuva natural, Lavras, MG

\begin{tabular}{|c|c|c|c|c|c|c|c|c|c|c|c|c|}
\hline \multirow{3}{*}{ Mês/ano } & \multicolumn{4}{|c|}{ Crotalária júncea } & \multicolumn{4}{|c|}{ Feijão-de-porco } & \multicolumn{4}{|c|}{ Milheto } \\
\hline & \multicolumn{2}{|c|}{$0,25 \mathrm{~m}$} & \multicolumn{2}{|c|}{$0,50 \mathrm{~m}$} & \multicolumn{2}{|c|}{$0,25 \mathrm{~m}$} & \multicolumn{2}{|c|}{$0,50 \mathrm{~m}$} & \multicolumn{2}{|c|}{$0,25 \mathrm{~m}$} & \multicolumn{2}{|c|}{$0,50 \mathrm{~m}$} \\
\hline & $\mathrm{Mg} \mathrm{ha}^{-1}$ & $\%$ & $\mathrm{Mg} \mathrm{ha}^{-1}$ & $\%$ & $\mathrm{Mg} \mathrm{ha}^{-1}$ & $\%$ & Mg ha $^{-1}$ & $\%$ & $\mathrm{Mg} \mathrm{ha}^{-1}$ & $\%$ & $\mathrm{Mg} \mathrm{ha}^{-1}$ & $\%$ \\
\hline Dez./2007 & 0,78 & 36,28 & 1,15 & 48,32 & 0,05 & 19,93 & 0,82 & 51,71 & 0,04 & 8,95 & 0,24 & 14,52 \\
\hline Jan./2008 & 0,35 & 16,28 & 0,09 & 3,78 & 0,09 & 39,24 & 0,33 & 20,86 & 0,07 & 15,67 & 0,27 & 16,10 \\
\hline Fev./2008 & 0,96 & 44,65 & 0,80 & 33,61 & 0,08 & 32,89 & 0,40 & 25,05 & 0,26 & 57,88 & 0,68 & 40,97 \\
\hline Mar./2008 & 0,06 & 2,79 & 0,34 & 14,29 & 0,02 & 7,94 & 0,04 & 2,38 & 0,08 & 17,50 & 0,47 & 28,41 \\
\hline Total & 2,15 & 100 & 2,38 & 100 & 0,24 & 100 & 1,59 & 100 & 0,45 & 100 & 1,66 & 100 \\
\hline Média & 0,54 & - & 0,60 & - & 0,06 & - & 0,40 & - & 0,11 & - & 0,42 & - \\
\hline DP & 0,41 & - & 0,47 & - & 0,03 & - & 0,32 & - & 0,10 & - & 0,21 & - \\
\hline CV (\%) & 75,99 & - & 79,43 & - & 55,70 & - & 81,38 & - & 88,91 & - & 49,31 & - \\
\hline
\end{tabular}


Tabela 3. Perdas de água em um Argissolo Vermelho-Amarelo, sob plantas de cobertura, para os espaçamentos de 0,25 e 0,50 m entrelinhas, nas condições de chuva natural, Lavras, MG

\begin{tabular}{|c|c|c|c|c|c|c|c|c|c|c|c|c|}
\hline \multirow{3}{*}{ Mês/Ano } & \multicolumn{4}{|c|}{ Crotalária júncea } & \multicolumn{4}{|c|}{ Feijão-de-porco } & \multicolumn{4}{|c|}{ Milheto } \\
\hline & \multicolumn{2}{|c|}{$0,25 \mathrm{~m}$} & \multicolumn{2}{|c|}{$0,50 \mathrm{~m}$} & \multicolumn{2}{|c|}{$0,25 \mathrm{~m}$} & \multicolumn{2}{|c|}{$0,50 \mathrm{~m}$} & \multicolumn{2}{|c|}{$0,25 \mathrm{~m}$} & \multicolumn{2}{|c|}{$0,50 \mathrm{~m}$} \\
\hline & $\mathrm{mm}$ & $\%$ & $\mathrm{~mm}$ & $\%$ & $\mathrm{~mm}$ & $\%$ & $\mathrm{~mm}$ & $\%$ & $\mathrm{~mm}$ & $\%$ & $\mathrm{~mm}$ & $\%$ \\
\hline Dez./2007 & 11,64 & 1,37 & 16,15 & 1,90 & 0,90 & 0,11 & 9,84 & 1,16 & 1,04 & 0,12 & 4,13 & 0,49 \\
\hline Jan/2008 & 4,37 & 0,51 & 4,68 & 0,55 & 1,72 & 0,20 & 4,71 & 0,55 & 1,69 & 0,20 & 4,78 & 0,56 \\
\hline Fev/2008 & 23,96 & 2,82 & 13,27 & 1,56 & 2,34 & 0,28 & 8,91 & 1,05 & 3,91 & 0,46 & 12,01 & 1,41 \\
\hline Mar/2008 & 1,95 & 0,23 & 10,67 & 1,26 & 1,04 & 0,12 & 2,48 & 0,29 & 2,96 & 0,35 & 10,21 & 1,20 \\
\hline Total & 41,92 & 4,93 & 44,77 & 5,27 & 6,00 & 0,71 & 25,94 & 3,05 & 9,60 & 1,13 & 31,13 & 3,66 \\
\hline Média & 10,48 & - & 11,19 & - & 1,50 & - & 6,48 & - & 2,40 & - & 7,78 & - \\
\hline DP & 9,89 & - & 4,88 & - & 0,66 & - & 3,48 & - & 1,28 & - & 3,92 & - \\
\hline CV (\%) & 94,32 & - & 43,63 & - & 44,30 & - & 53,63 & - & 53,51 & - & 50,37 & - \\
\hline
\end{tabular}

DP - desvio-padrão; CV - coeficiente de variação

no espaçamento de $0,25 \mathrm{~m}$ : milheto > crotalária júncea > feijãode-porco e no espaçamento de $0,50 \mathrm{~m}$ : crotalária júncea > milheto > feijão-de-porco; neste espaçamento as perdas também não seguiram a tendência de perdas de solo devido à maior cobertura do solo. É provável que a crotalária júncea contribuiu para uma evaporação menor, em virtude da maior cobertura vegetal; com isto, a umidade do solo se manteve elevada, sendo reduzida a taxa de infiltração de água no solo; consequentemente, ocorreu aumento do escoamento superficial, propiciando maiores perdas de água (Tabela 3). Os elevados valores dos coeficientes de variação ocorreram em razão da distribuição irregular das chuvas durante o período de estudo.

As perdas totais de água no Argissolo Vermelho-Amarelo estudado variaram de 6,00 a 44,77 mm, sob o feijão-de-porco no espaçamento de $0,25 \mathrm{~m}$ e sob a crotalária júncea no espaçamento de $0,50 \mathrm{~m}$, respectivamente. Carvalho et al. (2009) encontraram valores superiores de perdas de água em um Argissolo Vermelho-Amarelo sob crotalária júncea e milheto morro abaixo, sendo os valores de 65 e 208,7 mm, respectivamente. Silva et al. (2005) encontraram maiores valores de perdas anuais de água em solos descoberto, sendo no Cambissolo Háplico de $371 \mathrm{~mm}$ e no Latossolo Vermelho de $114 \mathrm{~mm}$; Brito et al. (2005) encontraram perdas anuais de água em sistemas florestais em Latossolo Vermelho de 23,66 mm e Pires et al. (2006) em Latossolo Vermelho-Amarelo registraram valores de $85,61 \mathrm{~mm}$.

$\mathrm{Na}$ Tabela 4 verificam as perdas de $\mathrm{P}, \mathrm{K}^{+}, \mathrm{Ca}^{2+}$ e $\mathrm{Mg}^{2+}$ contidos nos sedimentos após o processo erosivo. A precipitação e a adsorção do $\mathrm{P}$ reduziram sua quantidade na solução do solo motivo pelo qual foi o nutriente perdido em menor quantidade no sedimento erodido. O P perdido quase em sua totalidade estava ligado às partículas de solo, sendo a perda de $\mathrm{P}$ relacionada à quantidade de solo perdido em cada parcela. $\mathrm{O} \mathrm{Ca}^{2+}$ foi o nutriente perdido em maior quantidade nos solos sob crotalária júncea, feijão-de-porco e milheto, sendo que este nutriente se apresentava em maior quantidade no

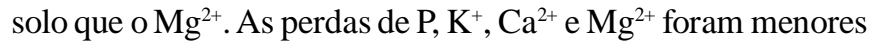
nos solos protegidos pelo feijão-de-porco, no espaçamento entre linhas de 0,25 m e maiores nos solos com crotalária júncea, no espaçamento de $0,50 \mathrm{~m}$ (Tabela 4 ), sendo que resultados semelhantes foram encontrados por Silva et al. (2005). O menor espaçamento propiciou perdas de $\mathrm{P}, \mathrm{K}^{+}, \mathrm{Ca}^{2+} \mathrm{e} \mathrm{Mg}^{2+}$ inferiores
Tabela 4. Perdas de $\mathrm{P}, \mathrm{K}^{+}, \mathrm{Ca}^{2+} \mathrm{e} \mathrm{Mg}^{2+}$ para um Argissolo Vermelho-Amarelo, sob plantas de cobertura, para os espaçamentos de 0,25 e 0,50 m de entrelinhas, nas condições de chuva natural, Lavras, MG

\begin{tabular}{ccccc}
\hline \multirow{2}{*}{ Tratamentos } & $\mathbf{P}$ & $\mathbf{K}^{+}$ & $\mathbf{C a}^{2+}$ & $\mathbf{M g}^{2+}$ \\
\cline { 2 - 5 } & \multicolumn{4}{c}{$\mathbf{k g ~ h a}^{-1}$} \\
$\mathrm{CJ}_{0,25}$ & 0,010 & 0,109 & 0,695 & 0,119 \\
$\mathrm{CJ}_{0,50}$ & 0,014 & 0,207 & 0,834 & 0,125 \\
$\mathrm{FP}_{0,25}$ & 0,001 & 0,015 & 0,070 & 0,012 \\
$\mathrm{FP}_{0,50}$ & 0,008 & 0,066 & 0,503 & 0,069 \\
$\mathrm{M}_{0,25}$ & 0,002 & 0,029 & 0,136 & 0,021 \\
$\mathrm{M}_{0,50}$ & 0,008 & 0,086 & 0,449 & 0,060 \\
\hline
\end{tabular}

$\mathrm{CJ}_{025}$ - Crotalária júncea 0,25 m; $\mathrm{CJ}_{0,50}$ - Crotalária júncea $0,50 \mathrm{~m} ; \mathrm{FP}_{025}$ - Feijão-de-porco 0,25 m; $\mathrm{FP}_{0,50}$ - Feijão-de-porco 0,50 m; $\mathrm{M}_{0,25}$ - Milheto $0,25 \mathrm{~m} \mathrm{e} \mathrm{M}_{0,50}$ - Milheto $0,50 \mathrm{~m}$

ao espaçamento de $0,50 \mathrm{~m}$ (Tabela 4); portanto, houve menores perdas de nutrientes visto que estas ocorrem simultaneamente com a perda de solos.

Não houve enriquecimento de $\mathrm{K}^{+}$e $\mathrm{Mg}^{2+}$ no sedimento erodido no cultivo de milheto, no espaçamento de $0,50 \mathrm{~m}$ (Tabela 5). A crotalária júncea e o milheto no espaçamento de $0,25 \mathrm{~m}$ apresentaram os maiores valores de taxa de enriquecimento do sedimento, com $\mathrm{Mg}^{2+}(1,5)$. As maiores taxas de enriquecimento do sedimento com $\mathrm{P}(2,6)$ e $\mathrm{K}^{+}(2,3)$ foram observadas nos solos sob crotalária júncea e com $\mathrm{Ca}^{2+}(1,5)$, sob feijão-deporco, no espaçamento de $0,50 \mathrm{~m}$, visto que a crotalária foi a espécie que menos protegeu o solo dos processos erosivos e, consequentemente, perdeu mais nutrientes.

No espaçamento de $0,25 \mathrm{~m}$ a sequência de taxa de enriquecimento do sedimento com a crotalária júncea e o feijãode-porco foi $\mathrm{P}>\mathrm{Mg}^{2+}>\mathrm{K}^{+}=\mathrm{Ca}^{2+}$ e com o milheto, $\mathrm{P}>\mathrm{K}^{+}>\mathrm{Ca}^{2+}$ $>\mathrm{Mg}^{2+}$. No espaçamento de $0,50 \mathrm{~m}$ a sequência de taxa de

Tabela 5. Taxa de enriquecimento do sedimento de um Argissolo Vermelho-Amarelo, sob plantas de cobertura, para os espaçamentos de 0,25 e 0,50 m entrelinhas, nas condições de chuva natural, Lavras, MG

\begin{tabular}{|c|c|c|c|c|c|c|}
\hline \multirow{2}{*}{ Nutrientes } & \multicolumn{6}{|c|}{ Plantas de cobertura } \\
\hline & $\mathbf{C J}_{0,25}$ & $\mathbf{C J}_{0,50}$ & $\mathrm{FP}_{0,25}$ & $\mathrm{FP}_{0,50}$ & $M_{0,25}$ & $M_{0,50}$ \\
\hline $\mathrm{P}\left(\mathrm{mg} \mathrm{dm}^{-3}\right)$ & 2,1 & 2,6 & 1,7 & 2,4 & 2,0 & 2,4 \\
\hline $\mathrm{K}\left(\mathrm{mg} \mathrm{dm^{-3 } )}\right.$ & 1,4 & 2,3 & 1,1 & 1,0 & 1,4 & 0,6 \\
\hline $\mathrm{Ca}^{2+}\left(\mathrm{cmol}_{\mathrm{c}} \mathrm{dm}^{-3}\right)$ & 1,4 & 1,4 & 1,1 & 1,5 & 1,2 & 1,1 \\
\hline $\mathrm{Mg}^{2+}\left(\mathrm{cmol}_{\mathrm{c}} \mathrm{dm}^{-3}\right)$ & 1,5 & 1,2 & 1,3 & 1,3 & 1,0 & 0,8 \\
\hline
\end{tabular}


enriquecimento de enxurrada foi com a crotalária júncea: $\mathrm{P}>\mathrm{K}^{+}$ $>\mathrm{Ca}^{2+}>\mathrm{Mg}^{2+}$; feijão-de-porco: $\mathrm{P}>\mathrm{Ca}^{2+}>\mathrm{Mg}^{2+}>\mathrm{K}^{+}$e milheto: $\mathrm{P}>\mathrm{Ca}^{2+}>\mathrm{Mg}^{2+}>\mathrm{K}^{+}$.

$\mathrm{Na}$ Figura 3 observa-se o potencial de arraste de sedimentos sob as plantas de cobertura estudadas nos espaçamentos de 0,25 e $0,50 \mathrm{~m}$. No espaçamento de $0,25 \mathrm{~m}$ os valores obtidos foram de 0,040, 0,047 e 0,051 $\mathrm{Mg} \mathrm{ha}^{-1} \mathrm{~mm}^{-1}$, para feijão-de-porco, milheto e crotalária júncea, respectivamente. No espaçamento de $0,50 \mathrm{~m}$ os valores obtidos foram de $0,053 \mathrm{Mg} \mathrm{ha}^{-1} \mathrm{~mm}^{-1} \mathrm{sob}$ crotalária júncea e milheto e de $0,061 \mathrm{Mg} \mathrm{ha}^{-1} \mathrm{~mm}^{-1}$ sob feijão-deporco. Este menor valor de potencial de arraste de sedimentos foi devido à proteção do solo e à maior produtividade de massa verde proporcionada pela maior densidade de plantas de cobertura por $\mathrm{m}^{2}$.

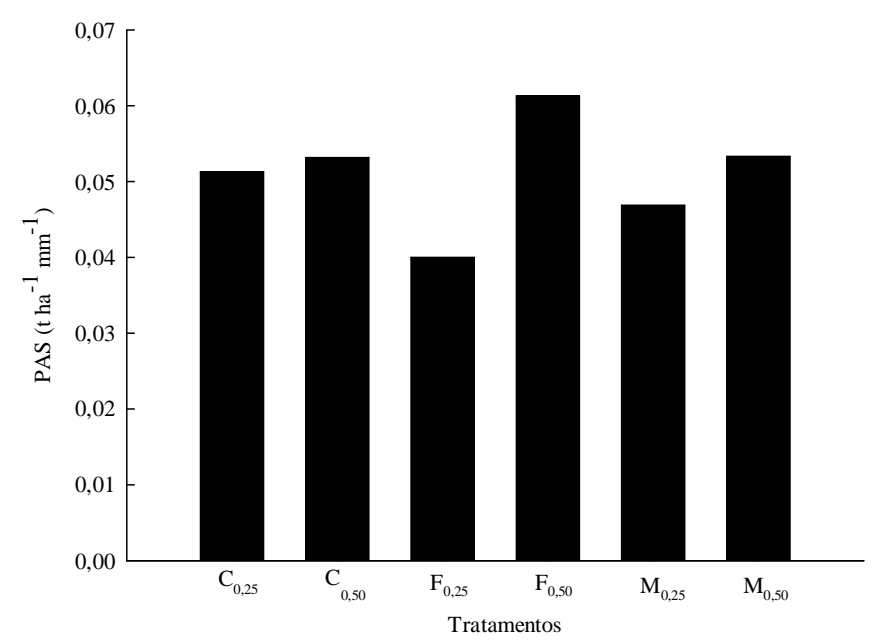

Figura 3. Potencial de Arraste de Sedimentos (PAS) em solo sob Crotalária júncea (CJ), Feijão-de-porco (FP) e Milheto (M), para os espaçamentos de 0,25 e 0,50 m de entrelinhas, nas condições de chuva natural, Lavras, MG

\section{Conclusões}

1. O maior índice de cobertura proporcionou o melhor crescimento e desenvolvimento de plantas de feijão-de-porco.

2. Entre as espécies de plantas de cobertura estudadas o feijãode-porco foi a que apresentou maior potencial no controle dos processos erosivos, pois propicia menores perdas de solo e água.

3. A melhor proteção do solo para todas as culturas foi obtida no espaçamento de $0,25 \mathrm{~m}$, haja vista que, quanto menor o espaçamento entre plantas mais entrelaçada fica a parte aérea, reduzindo as perdas de solo, água e nutrientes.

\section{LITERATURA CITADA}

Aguiar, M. I.; Maia, S. M. F.; Oliveira, T. S.; Mendonça, E. S.; Araújo Filho, J. A. Perdas de solo, água e nutrientes em sistemas agroflorestais no município de Sobral, CE. Revista Ciência Agronômica, v.37, p.270-278, 2006.

Bertol, I.; Cogo, N. P.; Schick, J.; Guadagnin, J. C.; Amaral, A. J. Aspectos financeiros relacionados às perdas de nutrientes por erosão hídrica em diferentes sistemas de manejo do solo. Revista Brasileira de Ciência do Solo, v.31, p.133-142, 2007.
Bertol, I.; Guadagnin, J. C.; Cassol, P. C.; Amaral, A. J.; Barbosa, F. T. Perdas de fósforo e potássio por erosão hídrica em um Inceptisol sob chuva natural. Revista Brasileira de Ciência do Solo, v.28, p.485-494, 2004.

Brito, L. F.; Silva, M. L. N.; Curi, N.; Leite, F. P.; Ferreira, M. M.; Pires, L. S. Erosão hídrica de Latossolo Vermelho muito argiloso relevo ondulado em área de pós-plantio de eucalipto no Vale do Rio Doce, região Centro Leste do Estado de Minas Gerais. Scientia Forestalis, v.67, p.27-36, 2005.

Carvalho, D. F.; Cruz, E. S.; Pinto, M. F.; Silva, L. D. B.; Guerra, J. G. M. Características da chuva e perdas por erosão sob diferentes práticas de manejo do solo. Revista Brasileira de Engenharia Agrícola e Ambiental, v.13, p.3-9, 2009.

Carvalho, R.; Silva, M. L. N.; Avanzi, J. C.; Curi, N.; Souza, F. S. Erosão hídrica em Latossolo Vermelho sob diversos sistemas de manejo do cafeeiro no sul de Minas Gerais. Revista Ciência e Agrotecnologia, v.31, p.1679-1687, 2007.

Cogo, N. P. Uma contribuição à metodologia de estudo das perdas por erosão em condições de chuva natural: I Sugestões gerais, medição do volume, amostragem e

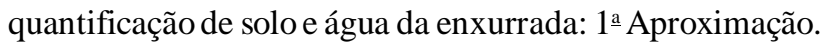
In: Encontro Nacional de Pesquisa sobre Conservação do Solo, 2., 1978, Passo Fundo. Anais... Passo Fundo: EmbrapaCNPT, 1978a. p.75-97.

Cogo, N. P. Uma contribuição à metodologia de estudo das perdas por erosão em condições de chuva natural: I Sugestões gerais, medição do volume, amostragem e quantificação de solo e água da enxurrada: 1aㅡ Aproximação. In: Encontro Nacional de Pesquisa sobre Conservação do Solo, 2., 1978, Passo Fundo. Anais... Passo Fundo: EmbrapaCNPT, 1978b. p.99-107.

Cogo, N. P.; Levien, R.; Schwarz, R. A. Perdas de solo e água por erosão hídrica influenciadas por métodos de preparo, classes de declive e níveis de fertilidade do solo. Revista Brasileira de Ciência do Solo, v.27, p.743-753, 2003.

Guadagnin, J. C.; Bertol, I.; Cassol, P. C.; Amaral, A. J. Perdas de solo, água e nitrogênio por erosão hídrica em diferentes sistemas de manejo. Revista Brasileira de Ciência do Solo, v.29, p.277-286, 2005.

Hernani, L. C.; Kurihara, C. H.; Silva, W. M. Sistemas de manejo de solo e perdas de nutrientes e matéria orgânica por erosão. Revista Brasileira de Ciência do Solo, v.23, p.145-154, 1999.

Leite, M. H. S.; Couto, E. G.; Amorim, R. S. S.; Costa, E. L.; Maraschin, L. Perdas de solo e nutrientes num Latossolo Vermelho-Amarelo ácrico típico, com diferentes sistemas de preparo e sob chuva natural. Revista Brasileira de Ciência do Solo, v.33, p.689-699, 2009.

Maria, I. C. de. Cálculo da erosividade da chuva. In: Instituto Agronômico de Campinas. Manual de programa de processamento de dados de campo e de laboratório para fins de experimentação em conservação do solo. Campinas: IAC-SCS, 1994.

Pires, L. S.; Silva, M. L. N.; Curi, N.; Leite, F. P.; Brito, L. F. Erosão hídrica pós-plantio em florestas de eucalipto na região centro-leste de Minas Gerais. Pesquisa Agropecuária Brasileira, v.41, p.687-695, 2006. 
Rufino, R. L. Avaliação do potencial erosivo da chuva para o estado do Paraná. Revista Brasileira de Ciência do Solo, v.10, p.279-281, 1986.

Silva, A. M.; Silva, M. L. N.; Curi, N.; Lima, J. M.; Avanzi, J. C.; Ferreira, M. M. Perdas de solo, água, nutrientes e carbono orgânico em Cambissolo e Latossolo sob chuva natural. Pesquisa Agropecuária Brasileira, v.40, p.1223-1230, 2005.
Wischmeier, W. H.; Smith, D. D. Rainfall energy and is relationships to soil loss. Transactions of the American Geophysical Union, v.39, p.285-291, 1958.

Zhou, G. Y.; Morris, J. D.; Yan, H. H.; Yu, Z. Y.; Peng, S. L. Hydrological impacts of reafforestation with eucalyptus and indigenous species: A case study in southern China. Forest Ecology and Management, v.167, p.209-222, 2002. 